\title{
Effects of inulin and fat percentage on the viability of Bifidobacterium lactis Bb12 in chocolate milk
}

\author{
Hadi Pourjafar ${ }^{1}$, Valiollah Ayareh ${ }^{2}$, Guity Karim ${ }^{3}$, Fereshteh Ansari ${ }^{4 *}$ and Hamid Kaboosi ${ }^{2}$ \\ ${ }^{1}$ Department of Public Health, Maragheh University of Medical Sciences, Maragheh, Iran \\ ${ }^{2}$ Islamic Azad University, Science and Research-Ayatollah Amoli Branch, Amol, Iran \\ ${ }^{3}$ Department of Food Hygiene, Tehran University, Tehran, Iran \\ ${ }^{4}$ Iranian evidence based center of excellence, Tabriz University of Medical Sciences, Iran
}

\begin{abstract}
Bifidobacterium genus has several beneficial effectsas a probiotic bacterium. It has been demonstrated that Inulin and fat percentage of the probiotic product may modify the viability of this bacterium during storage time. The aim of this study was finding the best formulation of the chocolate milk regarding bacterial viability and sensory properties of the final product. Four types of probiotic chocolate milk, with and without inulin in 1\% fat samples, with and without inulin in 2\% fat samples, were manufactured in duplicate. The count of probiotic cells during 12 days of storage in the refrigerator was assessed. In all samples, the viable cells of Bifidobacterium lactis increased except $1 \%$ fat samples without inulin in which bacterial count decreased (not significantly). The rate of change in the bacterial count was significantly $\mathrm{p}<0.05$ higher in the $2 \%$ fat chocolate milk both in with and without inulin samples (0.6 and 0.8 ) compared with $1 \%$ fat samples (0.5 and-0.4). Inulin inoculation had some effects on biochemical and organoleptic changes. After 12 days storage, the acceptability of $2 \%$ fat milk with probiotic and inuline was the highest. The results illustrated that the most significant Bifidobacterium lactis viability was in $2 \%$ fat chocolate milk. Adding inulin improved the viability of bacteria in 1\% fat milk; however, ithad not any significant effects on the viability of probiotic bacteria in $2 \%$ fat milk. In conclusion, $2 \%$ fat chocolate milk with inuline could be recommended to be the best group.
\end{abstract}

KEY WORDS: BIFIDOBACTERIUM LACTIS, CHOCOLATE MILK, INULIN, VIABILITY

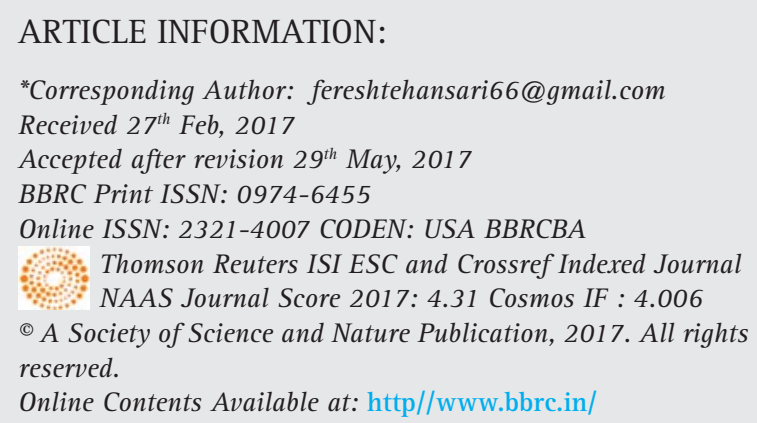




\section{INTRODUCTION}

Nowadays the acceptability of probiotic products is increasing across the world, especiallyin Europe, USA, and Japan. More than $90 \%$ of probiotic food products contain Lactobacilli and Bifidobacteria (Gueimonde et al. 2004, Hemalatha et al. 2017, Zoumpopoulou et al. 2017).

Bifidobacterium genus is one of the most important genera of probiotic bacteria. It was isolated for the first time from breastfeed newborns' feces by Tisser in 1906 . This bacterium helps food digestion by secretion enzymes like beta-galactosidase and protease. Suppressing the intestinal infective bacteria, producing some vitamins, anti-cancer and anti-mutation properties, immune system stimulation, reducing blood serum cholesterol, and increasing calcium absorption are some of its other beneficial effects. Bifidobacterium lactis is the most usable Bifidobacteria in probiotic dairy products (dos Santos Cruxen et al. 2017, Gomes and Malcata 1999, Monteagudo-Mera et al. 2016, Novak and Katz 2006, Poutsiaka et al. 2017).

Inulins are a group of fructooligosaccharides mainly extracted from chicory root. Inulin is non-digestible; therefore, passes throughout the small intestine and isfermented in the colon. Inulin may be able to feed and stimulate the growth and propagation of Bifidobacteria species and other probiotics in the colon (Guarino et al. 2017, Lightowler et al. 2017, Lopes et al. 2017, ValdésVarela et al. 2017, Vandeputte et al. 2017).

Dairy products provide an important portion of the essential nutrientsin every age group. These days unfermented andflavoured probiotic milks are drawing the attention of researchers and industrialists due to theirsensory properties, increasing consumption, and nutritional value. Therefore, by using chocolate milk as a carrier for probiotics, we can improve the healthiness level of society (Ashurst 2016, Aune et al. 2015, Henry et al. 2015, Oliveira et al. 2017).

The objective of this study was finding the best composition of the probiotic bacteria (Bifidobacteria) and prebiotic (inulin) regarding bacterial viability and sensory properties of the chocolate milk as the final product. Chocolate milk can be industrially produced with different percentages of fat. In this study, we used $1 \%$ and $2 \%$ fat containing chocolate milk to examine the effects of increased fat on the final product. To our knowledge, it is the first time that the effects of inulin and fat percentage are concurrently studied in probiotic chocolate milk.

\section{MATERIAL AND METHODS}

\section{Sample production method and its volume}

The sterile chocolate milk was prepared. And then, common microbial control tests (total count and Enterobac- teriaceae) were conducted based on Iran National Standard. The Bifidobacteriumx lactis Bb12 was obtained from a Dutch company (DSM) asa direct vat set (DVS). They were cultured in MRS broth in anaerobic condition. Then, they were incubated at $37^{\circ} \mathrm{C}$ for 18 hours.

According to the manufacturer's instruction, $0.1 \%$ of the bacteria was added to the normal salineand incubated at $37^{\circ} \mathrm{C}$ for $18 \mathrm{~h}$ to reach the logarithmic growth. Then, they were added to sterile milk with 1 and 2 percent fat. Both of the milk percentages were divided into two parts. A 0.5\% sterile inulin (Belgium Co.) was added into one part of each sample. Another part of each sample was left without inulin. Two other samples were selected as controls. Each of the samples ( 6 samples) was divided into 8 bottles of $100 \mathrm{ml}$ capacity (total, 48 bottles). A two- liter containing bottle of each sample was stored in the $5^{\circ} \mathrm{C}$ refrigeratorto taste panel test. The bottles with a dilution of 10-3 to 10-7were cultured in anaerobic MRS agar (MEREK, Germany) and type A gas pack (MEREK, Germany), then incubated at $37^{\circ} \mathrm{C}$ for $96 \mathrm{~h}$. At the end of 96 hthe colony counting was conducted using the colony counter (Klindt-Toldam et al. 2016, Mirzaei et al. 2012, Mirzaei et al. 2011, Pourjafar et al. 2016).

\section{Biochemical indices}

Physicochemical properties ( $\mathrm{pH}$, acidity, and viscosity) were measured; and, organoleptice valuation was conducted at each time of culturing. Evaluation of $\mathrm{pH}$ : The samples' $\mathrm{pH}$ was measured during refrigerated storage using the $\mathrm{pH}$-meter. The device was calibrated using standard buffers (pH4, pH7). Aciditymeasurements: In order to measure titrable acidity $10 \mathrm{ml}$ of sample and $10 \mathrm{ml}$ distilled water was poured into Erlenmeyer flasks and 0.1 normal salinewas titratedat the presence of phenolphthalein. The rate of the index was measured using Dornic degree as follows a formula: Titrable acidity (Dornicdegree) $=$ usedsaline volume $(\mathrm{ml}) \times 9$ : Viscosity measurement The viscosity of the samples was measured using refractometer (Zherber Co.) during refrigerated storage. Sensory evaluation: chocolate milk samples were examined by 15 experts on the days 4 and 12 . They used scoring methodto evaluate sensory properties of the chocolate milk, such as flavor, smell, sweetness, and viscosity based on the score 10 . Total results were evaluated based on 20 scores (Marsanasco et al. 2015, Mirzaei et al. 2012).

\section{Statistical analysis}

Bacterial count was measured in days 0, 4, 8 and 12 in duplicate. The rate of changes in bacterial count from the first day to twelfth day was compared across groups using ANOVA test and post hoc Bonferroni test. Further, SPSS-IBM 21 was used for statistical analysis. $\mathrm{P}<0.05$ 

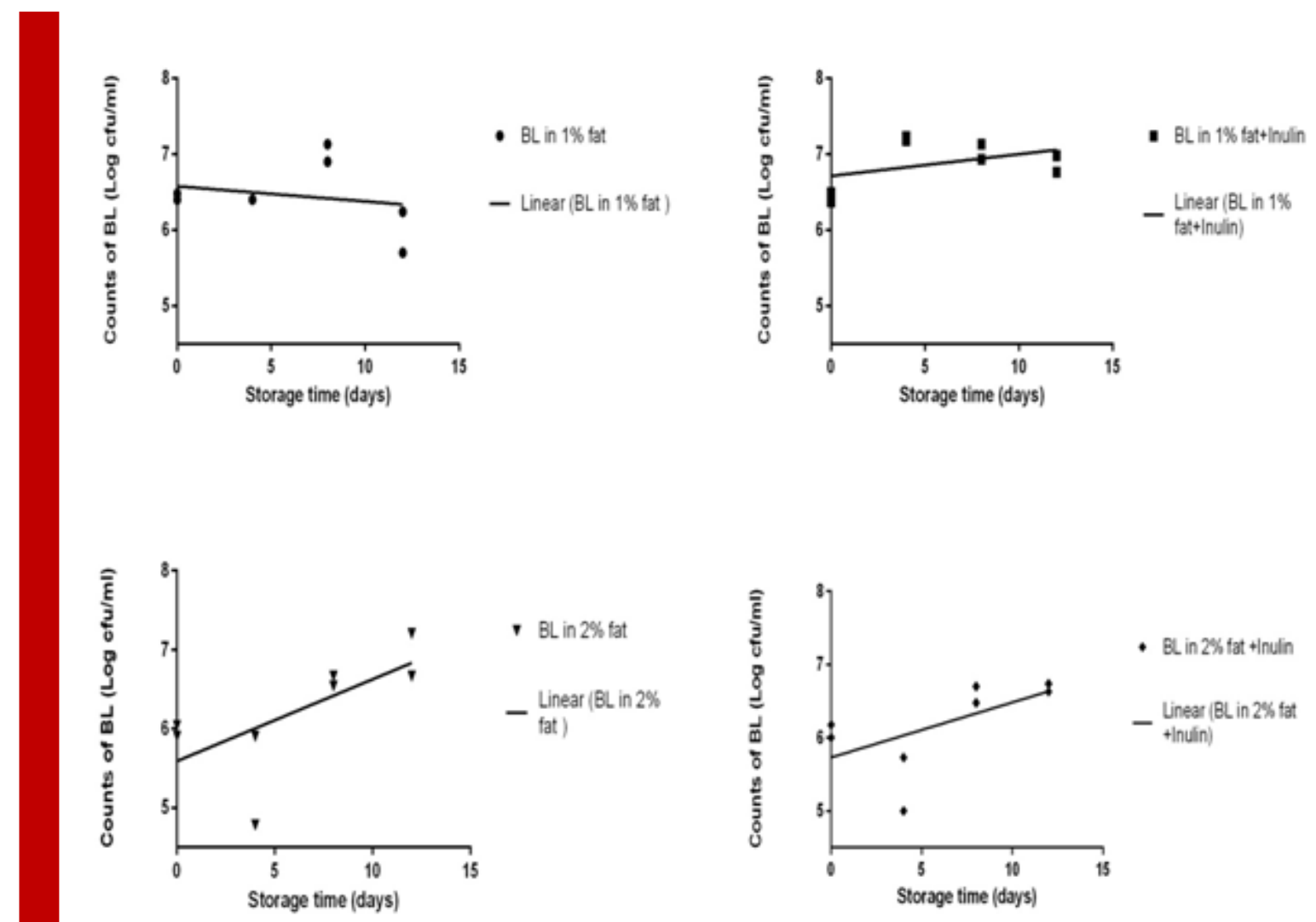

FIGURE 1. Survival of B. lactis (BL) cells in chocolate milk during 12 days storage in the refrigerator (Duplicate bacterial count).

was considered as significance level. Graphpad prism ver. 6 used for drawing the graphs.

\section{RESULTS AND DISCUSSION}

In all samples, bacterial count increased after 12 days except 1\% fat samples without inulin in which bacterial count decreased. The rate of increase the bacterial count was higher in $2 \%$ fat milk (both with and without inulin samples) compared with $1 \%$ fat milk. The change in bacterial count was significantly different between $1 \%$ fat milk with and without inulin samples, but we did not observe any significant differences between 2\% fat milk with and without inulin in this case (See table1). Variations in counts of B. lactis during 12 days storage period in the refrigerator (cfu ml-1) are shown in Fig. 1.

The viscosity of $2 \%$ fat milk was higher than $1 \%$ fat milk. In samples containing inulin, the viscosity was higher than inulin free samples with comparable fat percentages. Viscosity did not change during storage period. There has been just a small increase in the viscosity of samples containing inulin with both $1 \%$ and $2 \%$ fat. Acidity was similar in all study groups and stayed constant during the research period. $\mathrm{pH}$ was higher in $2 \%$ fat samples and samples containing inulin had higher $\mathrm{pH}$ in comparison with control and probiotic without inulin samples with the similar fat percentage. $\mathrm{pH}$ reduced slightly during 12 days in all samples. In $2 \%$ fat samples containing inulin $\mathrm{pH}$ reduction was the highest (See table 2).

The 1\%-fat chocolate milk with and without inulin sample was examined and compared to the control sample (probiotic-free) by 15 experts on the days 4 and 12 during refrigerated storage. The most and least acceptable groups after 4 days storage were 1\% fat probiotic milk with inulin and 1\% fat probiotic without inulin. After 12 days milks with 2\% fat were generally more acceptable than $1 \%$ fat. Samples containing inulin and probiotic and at the second stage samples with probiotic and without inulin were more acceptable than control groups with similar fat percentage (See table 3).

There are many studies that confirm the role of inulin in improving sensory quality, enhancing the probiotic viability, asa prebiotic, fat replacer and texturizerin some potentially synbiotic dairy products; for instance 
Table 1 . The Mean \pm standard deviation of $\log 10$ of duplicate probiotic count in $1 \%$ and $2 \%$ fat milk (without probiotic, with probiotic, with both probiotic and inulin) during 12 days storage in the refrigerator in 104 dilution (n/group. day=4).

\begin{tabular}{|l|l|l|l|l|l|}
\hline & \multicolumn{3}{|l|}{$1 \%$ Fat } & $2 \%$ Fat \\
\hline & Storage day & Probiotic $^{\mathrm{a}}$ & ${\text { Probiotic } \text { \& } \text { Inulin }^{\mathrm{b}}}$ & Probiotic $^{\mathrm{C}}$ & Probiotic Ct Inulin $^{\mathrm{c}}$ \\
\hline Bacterial count & 0 & $6.4 \pm 0.1$ & $6.4 \pm 0.1^{\mathrm{A}}$ & $6.0 \pm 0.1$ & $6.1 \pm 0.1^{\mathrm{AB}}$ \\
\hline & 4 & $6.4 \pm 0.0$ & $7.2 \pm 0.0^{\mathrm{B}}$ & $5.3 \pm 0.8$ & $5.4 \pm 0.5^{\mathrm{B}}$ \\
\hline & 8 & $7.0 \pm 0.2$ & $7.0 \pm 0.1^{\mathrm{AB}}$ & $6.6 \pm 0.1$ & $6.6 \pm 0.2^{\mathrm{AB}}$ \\
\hline & 12 & $6.0 \pm 0.4$ & $6.9 \pm 0.2^{\mathrm{AB}}$ & $6.9 \pm 0.4$ & $6.7 \pm 0.1^{\mathrm{A}}$
\end{tabular}

The result of two way ANOVA test showed that there was a significant difference between the bacterial count in different examination days $(\mathrm{P}=0.004)$ and different groups $(\mathrm{P}<0.001)$. There was also a significant difference between the change of bacterial count during storage time in different groups $(\mathrm{P}=002)$. The groups shown by different lowercase letters have statistical difference. Statistical differences between days in each group are shown by different uppercase letters.

Table 2. The results of the biochemical characteristics of $1 \%$ and $2 \%$ fat milk (without probiotic, with probiotic, with both probiotic and inulin) during 12 days storage in the refrigerator.

\begin{tabular}{|c|c|c|c|c|c|c|c|}
\hline & & $1 \%$ Fat & & & $2 \%$ Fat & & \\
\hline & Storage day & Control & Probiotic & Probiotic \& Inulin & Control & Probiotic & Probiotic \& Inulin \\
\hline \multirow[t]{4}{*}{ Viscosity } & 0 & 17.1 & 17.1 & 17.2 & 16.1 & 16.1 & 16.2 \\
\hline & 4 & 17.1 & 17.1 & 17.15 & 16.1 & 16.1 & 16.2 \\
\hline & 8 & 17 & 17.1 & 17.3 & 16.15 & 16.1 & 16.25 \\
\hline & 12 & 16.9 & 17.1 & 17.3 & 16.15 & 16.1 & 16.35 \\
\hline \multirow[t]{4}{*}{ Acidity } & 0 & 15 & 15 & 15 & 15 & 15 & 15 \\
\hline & 4 & 15 & 15 & 15 & 15 & 15 & 15 \\
\hline & 8 & 15 & 15 & 15 & 15 & 15 & 15 \\
\hline & 12 & 15 & 15 & 15 & 15 & 15 & 15 \\
\hline \multirow[t]{4}{*}{$\mathrm{pH}$} & 0 & 6.6 & 6.6 & 6.75 & 6.7 & 6.7 & 6.75 \\
\hline & 4 & 6.62 & 6.6 & 6.62 & 6.7 & 6.69 & 6.73 \\
\hline & 8 & 6.59 & 6.6 & 6.63 & 6.7 & 6.71 & 6.73 \\
\hline & 12 & 6.59 & 6.58 & 6.62 & 6.68 & 6.68 & 6.72 \\
\hline
\end{tabular}

Table 3. The mean and standard deviation of the organoleptic acceptability of $1 \%$ and $2 \%$ fat milk (without probiotic, with probiotic, with both probiotic and inulin) after 4 and 12 days storage in the refrigerator (examined by 15 experts).

\begin{tabular}{|l|l|l|l|l|l|l|l|}
\hline & & $1 \%$ Fat & & & $2 \%$ Fat & & \\
\hline & Properties & Control & Probiotic & Probiotic Ct Inulin & Control & Probiotic & Probiotic Ct Inulin \\
\hline Day 4 & Flavor (from 10) & 5.7 & 5.3 & 6.6 & 6.5 & 6.5 & 6.7 \\
\hline & Smell (from 10) & 5.2 & 4.9 & 6 & 6 & 6.1 & 6.4 \\
\hline & Sweetness (from 10) & 6.1 & 5.8 & 6.9 & 4.5 & 5.5 & 5.5 \\
\hline & Viscosity (from 10) & 5.4 & 5.9 & 6.5 & 6.36 & 6.72 & 6.45 \\
\hline & Total result (from 20) & $14.6 \pm 0.7$ & $14.1 \pm 0.6$ & $15.6 \pm 0.5$ & $14.4 \pm 0.5$ & $15.2 \pm 0.7$ & $14.9 \pm 0.6$ \\
\hline Day 12 & Flavor (from 10) & 5.3 & 5.9 & 6 & 5.8 & 6.45 & 7.09 \\
\hline & Smell (from 10) & 5.1 & 5.9 & 5.6 & 6.1 & 6.2 & 6.2 \\
\hline & Sweetness (from 10) & 6.1 & 6.2 & 7.4 & 6 & 7.1 & 6.4 \\
\hline & Viscosity (from 10) & 6 & 5.7 & 6.1 & 6.09 & 6.2 & 6.2 \\
\hline & Total result (from 20) & $13.0 \pm 0.7$ & $13.5 \pm 0.8$ & $14.5 \pm 0.4$ & $14.1 \pm 0.7$ & $14.3 \pm 0.7$ & $15.4 \pm 0.5$ \\
\hline
\end{tabular}


ice-cream, yogurt, cheese and other fermented dairy beverages (Cardarelli et al. 2008, de Souza et al. 2017, Guggisberg et al. 2009, Karimi et al. 2015, Kolida et al. 2002, Valero-Cases and Frutos 2017). de Souza et al. (2017) studiedthe effect of inulin in different proportions up to $3 \%$, on the survivability and resistance to simulated gastrointestinal conditions of Bifidobacterium animalis $\mathrm{Bb} 12$ added in probiotic and synbiotic margarine. In this study, Inulin enhanced $\mathrm{Bb} 12$ survival significantly $(\mathrm{P}<0.05)$ (de Souza et al. 2017). ValeroCases and Frutos (2017) investigated the prebiotic effect of diverse concentrations of inulin (0,1 and 2\%) on the growth and viability of Lactobacillus plantarum CECT 220 in mixed carrot and orange juices. Throughout storage time, the inulin improved the survivability of Lactobacillus plantarum and the monosaccharide concentration remained upper regarding the juice without inulin (40\% lower). At 30 days, the fermented juices with 2\% inulin following in vitro digestion presented the maximum viability of Lactobacillus plantarum (Valero-Cases and Frutos 2017).

To the best of our knowledge, present study is the first work that shows the effects of inulin and fat percentage concurrently on the viability of Bifidobacterium lactis.

According to the results of this investigation, the most important status for the viability of Bifidobacterium lactis was in 2\% fat chocolate milk. We conclude that the viability of this probiotic bacterium is higher in samples with higher fat content, and adding inulin may increase the viability of bacteria in low fat milk (1\%) but not in high fat milk (2\%). Inulin inoculation had some effects on biochemical and organoleptic changes. In sensory examination, all groups were more favorable than the control sample (without the probiotic bacterium and inulin). It is suggested that chocolate milk with $2 \%$ fat and inulin be as a more effective probiotic dairy product.

\section{REFERENCES}

Ashurst, P. R. (2016) Chemistry and technology of soft drinks and fruit juices, John Wiley \&t Sons. West Sussex, P019 8SQ, UK.

Aune, D., Rosenblatt, D. A. N., Chan, D. S., Vieira, A. R., Vieira, R., Greenwood, D. C., Vatten, L. J. and Norat, T. (2015) Dairy products, calcium, and prostate cancer risk: a systematic review and meta-analysis of cohort studies. The American journal of clinical nutrition, pp. ajcn. 067157.

Cardarelli, H. R., Buriti, F. C., Castro, I. A. and Saad, S. M. (2008) Inulin and oligofructose improve sensory quality and increase the probiotic viable count in potentially synbiotic petit-suisse cheese. LWT-Food Science and Technology, Vol. 41, No. 6, pp. 1037-1046.

de Souza, C. H. B., Gioielli, L. A. and Saad, S. M. I. (2017) Inulin increases Bifidobacterium animalis Bb-12 in vitro gastrointes- tinal resistance in margarine. LWT-Food Science and Technology, Vol. 79, pp. 205-212.

dos Santos Cruxen, C. E., Hoffmann, J. F., Zandoná, G. P., Fiorentini, Â. M., Rombaldi, C. V. and Chaves, F. C. (2017) Probiotic butiá (Butia odorata) ice cream: Development, characterization, stability of bioactive compounds, and viability of Bifidobacterium lactis during storage. LWT-Food Science and Technology, Vol. 75, pp. 379-385.

Gomes, A. M. and Malcata, F. X. (1999) Bifidobacterium spp. and Lactobacillus acidophilus: biological, biochemical, technological and therapeutical properties relevant for use as probiotics. Trends in Food Science \&t Technology, Vol. 10, No. 4, pp. 139-157.

Guarino, M. P. L., Altomare, A., Barera, S., Locato, V., Cocca, S., Franchin, C., Arrigoni, G., Vannini, C., Grossi, S. and Campomenosi, P. (2017) Effect of Inulin on Proteome Changes Induced by Pathogenic Lipopolysaccharide in Human Colon. PLoS ONE, Vol. 12, No. 1, pp. e0169481.

Gueimonde, M., Delgado, S., Mayo, B., Ruas-Madiedo, P., Margolles, A. and de los Reyes-Gavilán, C. G. (2004) Viability and diversity of probiotic Lactobacillus and Bifidobacterium populations included in commercial fermented milks. Food Research International, Vol. 37, No. 9, pp. 839-850.

Guggisberg, D., Cuthbert-Steven, J., Piccinali, P., Bütikofer, U. and Eberhard, P. (2009) Rheological, microstructural and sensory characterization of low-fat and whole milk set yoghurt as influenced by inulin addition. International dairy journal, Vol. 19, No. 2, pp. 107-115.

Hemalatha, R., Ouwehand, A., Saarinen, M., Prasad, U., Swetha, K. and Bhaskar, V. (2017) Effect of probiotic supplementation on total lactobacilli, bifidobacteria and short chain fatty acids in 2-5-year-old children. Microbial Ecology in Health and Disease, Vol. 28, No. 1, pp. 1298340.

Henry, C., Whiting, S. J., Phillips, T., Finch, S. L., Zello, G. A. and Vatanparast, H. (2015) Impact of the removal of chocolate milk from school milk programs for children in Saskatoon, Canada. Applied Physiology, Nutrition, and Metabolism, Vol. 40, No. 3, pp. 245-250.

Karimi, R., Azizi, M. H., Ghasemlou, M. and Vaziri, M. (2015) Application of inulin in cheese as prebiotic, fat replacer and texturizer: A review. Carbohydrate Polymers, Vol. 119, pp. 85-100.

Klindt-Toldam, S., Larsen, S. K., Saaby, L., Olsen, L. R., Svenstrup, G., Müllertz, A., Knøchel, S., Heimdal, H., Nielsen, D. S. and Zielińska, D. (2016) Survival of Lactobacillus acidophilus $\mathrm{NCFM}^{\circledR}$ and Bifidobacterium lactis HNO19 encapsulated in chocolate during in vitro simulated passage of the upper gastrointestinal tract. LWT-Food Science and Technology, Vol. 74, pp. 404-410.

Kolida, S., Tuohy, K. and Gibson, G. R. (2002) Prebiotic effects of inulin and oligofructose. British Journal of Nutrition, Vol. 87, No. S2, pp. S193-S197.

Lightowler, H., Thondre, S., Holz, A. and Theis, S. (2017) Replacement of glycaemic carbohydrates by inulin-type fructans from chicory (oligofructose, inulin) reduces the 
postprandial blood glucose and insulin response to foods: report of two double-blind, randomized, controlled trials. European Journal of Nutrition, pp. 1-10.[Epub ahead of print].

Lopes, S. M. S., Krausová, G., Carneiro, J. W. P., Gonçalves, J. E., Gonçalves, R. A. C. and de Oliveira, A. J. B. (2017) A new natural source for obtainment of inulin and fructo-oligosaccharides from industrial waste of Stevia rebaudiana Bertoni. Food chemistry,Vol. 225, pp. 154-161.

Marsanasco, M., Márquez, A. L., Wagner, J. R., Chiaramoni, N. S. and Alonso, S. d. V. (2015) Bioactive compounds as functional food ingredients: characterization in model system and sensory evaluation in chocolate milk. Journal of Food Engineering, Vol. 166, pp. 55-63.

Mirzaei, H., Pourjafar, H. and Homayouni, A. (2012) Effect of calcium alginate and resistant starch microencapsulation on the survival rate of Lactobacillus acidophilus La5 and sensory properties in Iranian white brined cheese. Food chemistry, Vol. 132, No. 4, pp. 1966-1970.

Mirzaei, H., Pourjafar, H. and Rad, A. H. (2011) The effect of microencapsulation with calcium alginate and resistant starch on the Lactobacillus acidophilus (La5) survival rate in simulated gastrointestinal juice conditions. Journal of Veterinary Research, Vol. 66, No. 4, pp. 337-342.

Monteagudo-Mera, A., Arthur, J., Jobin, C., Keku, T., BrunoBarcena, J. and Azcarate-Peril, M. (2016) High purity galactooligosaccharides enhance specific Bifidobacterium species and their metabolic activity in the mouse gut microbiome. Beneficial microbes, Vol. 7, No. 2, pp. 247-264.

Novak, J. and Katz, J. A. (2006) Probiotics and prebiotics for gastrointestinal infections. Current infectious disease reports, Vol. 8, No. 2, pp. 103-109.

Oliveira, D., Vidal, L., Ares, G., Walter, E. H., Rosenthal, A. and Deliza, R. (2017) Sensory, microbiological and physicochemi- cal screening of probiotic cultures for the development of nonfermented probiotic milk. LWT-Food Science and Technology, Vol. 79, pp. 234-241.

Pourjafar, H., Noori, N., Gandomi, H. and Akhondzadeh Basti, A. (2016) Study of protective role of double coated beads of calcium alginate-chitosan-eudragit s100 nanoparticles achieved from microencapsulation of Lactobacillus acidophilus as a predominant flora of human and animals gut. Journal of Veterinary Research, Vol. 71, No. 3, pp. 311-320.

Poutsiaka, D. D., Mahoney, I., McDermott, L., Stern, L., Thorpe, C., Kane, A., Baez-Giangreco, C., McKinney, J., Davidson, L. and Leyva, R. (2017) Selective method for identification and quantification of Bifidobacterium animalis subspecies lactis BB-12 (BB-12) from the gastrointestinal tract of healthy volunteers ingesting a combination probiotic of BB-12 and Lactobacillus rhamnosus GG. Journal of Applied Microbiology, Vol. 122, No. 5, pp. 1321-1332.

Valdés-Varela, L., Ruas-Madiedo, P. and Gueimonde, M. (2017) In vitro fermentation of different fructo-oligosaccharides by Bifidobacterium strains for the selection of synbiotic combinations. International journal of food microbiology, Vol. 242, pp. 19-23.

Valero-Cases, E. and Frutos, M. J. (2017) Effect of Inulin on the Viability of L. plantarum during Storage and In Vitro Digestion and on Composition Parameters of Vegetable Fermented Juices. Plant Foods for Human Nutrition, pp. 1-7.

Vandeputte, D., Falony, G., Vieira-Silva, S., Wang, J., Sailer, M., Theis, S., Verbeke, K. and Raes, J. (2017) Prebiotic inulintype fructans induce specific changes in the human gut microbiota. Gut, pp. gutjnl-2016-313271.

Zoumpopoulou, G., Pot, B., Tsakalidou, E. and Papadimitriou, K. (2017) Dairy probiotics: Beyond the role of promoting gut and immune health. International dairy journal, Vol. 67, pp. 46-60. 